\title{
Stress: The Insidious Leveler of Good, Unsuspecting, Online Instructors of Higher Education
}

\author{
Gina S. Smith \\ Walden University \\ Henry M. Brashen \\ Walden University \\ Maria A. Minor \\ Kaplan University \\ Peter J. Anthony \\ Walden University
}

\begin{abstract}
This study was undertaken to determine the effects of stress on faculty in higher education teaching online classes. Few studies have been conducted to examine the impact of stress on faculty in online higher education. An anonymous survey of faculty was conducted at an online institution of higher learning to determine how prevalent stress was in their jobs, how stress impacted performance and morale, and what the symptoms were. The findings showed $67.6 \%$ of the 100 participants who completed the survey identified either a very high or high level of stress. The biggest stressors included time constraints, technical issues, and large class sizes. The top symptoms identified included sleep disturbances, impatience, tense, tight muscles, irritability, and the feeling of being overwhelmed. Recommendations were made to alleviate stress including physical activity, constructive self-talk, relaxation exercises, meditation, networking, quick and effective coping skills, and techniques for saying "no." A certain amount of stress is desirable, but when stress is not addressed, it can lead to burnout, poor performance, and low morale.
\end{abstract}

Keywords: stress, online instructors, higher education

\section{Introduction}

Stress manifests itself in a variety of ways. Unmanaged stress can lead to serious declines in productivity, morale, and overall health. The purpose of this article is to explore the symptoms and impact of stress in online instructors. Participants included online faculty working in a large online university. Our sample included voluntary participants we sought out through an invitational email for a sample of convenience.

Much research has been devoted to studying the effects of stress on the American workforce as well as higher education faculty. However, very little, if any, research has been done on the effects of stress on higher education faculty who teach online. When the demands on your body exceed the ability to cope, you have stress. Burnout is the ultimate end of untreated stress. People can function 
effectively with stress for a long time, but eventually, the wear and tear on the body physically, mentally, and emotionally will result in burnout (Maslach, Jackson, \& Leiter, 1996). The problem is the lack of research related to the effects of stress on higher education faculty who teach online.

We selected a qualitative method to seek information related to online instructors' lived experiences related to stress. We employed a survey, as there is very little research on this topic. Our sample was selected by convenience because we have access to a substantial sample size of online faculty. Analysis of data occurred through the exploration of themes related to survey question answers. Research questions included the following:

- To what extent does stress occur in higher education online instructors?

- To the extent stress does occur, what are the symptoms that are displayed?

- How does stress impact performance and morale of online instructors?

\section{Literature on Stress in the American Workplace, Causes of Job Stress, Behavior Types, and Work-Life Balance}

Stress can be explained using a variety of definitions. For the purpose of this article, stress was defined as "the adverse reaction of every individual person who happens to experience so much pressure and other types of demand of workload placed upon his/her ability to adapt it" (Betonio, 2015 , p. 651). The definition of stress can be narrowed down to mean the "normal physical response to events in life that makes you feel threatened or distorts your equilibrium" ("Stress," 2011, para 1). Every human being experiences some form of stress in life and reacts to stress in a variety of ways. Some people may have physical reactions while others lean towards emotional ways of dealing with stress. Stress reactions are individual and unique.

\section{Scope of Stress in the American Workplace}

Workplace stress, if ignored, can be costly to a business. The Center for the Promotion of Health in the New England Workplace (2015) noted that job stress costs U.S. industries up to $\$ 300$ billion annually. Stress in the workplace leads to higher rates of accidents, absenteeism, employee turnover, decreased productivity, substance abuse, and higher medical, legal, and insurance costs (Singh, Tripathi, Yadav, 2010, p. 184). In a 2012 American Psychological Association (APA) workplace survey conducted online, $41 \%$ of 1,714 working respondents felt tense and stress during the workday. Yearly results showed the rates are up from 36\% in the 2011 APA survey. Miller (1994) identified a link between workplace stress and health of employees. He noted that higher stress levels increased the likelihood of poorer health among employees.

Business leaders may experiences losses of $\$ 200-\$ 300$ billion annually to stress-related issues. Ninety percent of all doctor visits are for stress related disorders. Ninety-five million people take medication weekly to reduce stress symptoms. Stress causes $80-85 \%$ of all illnesses and disease (American Institute of Stress, n.d.). Stress in the workplace is a fact of life.

\section{What Are the Causes of Job Stress?}

The top five factors that contribute to stress are low salaries, lack of opportunity for advancement and growth, heavy workload, long hours, and lack of or uncertain job expectations (APA, 2012). The survey identified a direct correlation between those that reported feeling undervalued with higher rates of stress. A past survey conducted by Miller (1994) identified the most common cause of stress 
as being unreasonable deadlines, unclear job expectations, and lack of feedback. Over the span of 20 years, the top causes of stress have not changed or improved.

\section{Type A and B Behaviors}

Individuals with Type A behavior tend to multitask as a necessity and become agitated when their schedule is interrupted or when changes occur that they currently don't have control over (Friedman \& Rosenman, 1974). Online instructors tend to multitask and take on more work than is possible to be performed in a normal workday. Type A individuals may experience elevated levels of stress when their daily schedule adjusts more than they have the ability to control. Individuals with Type B behavior tend to be able to relax more often than Type A individuals, and Type B individuals are more patient (Friedman \& Rosenman, 1974). Online instructors may display a combination of both Types A and B in various combinations under various circumstances. A climate where an instructor feels overworked may cause online instructors to experience various levels of Type A or Type B behavioral stress (Mazzetti, Schaufeli, \& Guglielmi, 2014). Understanding the situations that cause an online instructor to lean more toward Type A or Type B may provide information for dealing with the stress before the stress takes control.

\section{Work-Life Balance}

Online faculty members constantly balance time throughout every day with work, life, and online teaching. Demanding culture of online teaching, stressful work conditions, and limited time contribute to stress (Ross \& Vasantha, 2014). Findings from a study conducted in 2013 with faculty at University of Calfornia, Los Angeles, indicated an opportunity for educational leaders to address faculty work-life balance through faculty training concentrated on strategies for faculty to allocate realistic time to (a) family, (b) work, (c) life, (d) teaching, and (e) personal health (UCLA Faculty Diversity and Development, 2013). A descriptive study using Delphi methodology was conducted in 2006 to examine stress and job satisfaction among distance educators (McLean, 2006). The findings of the study indicated the greatest stress on online faculty to be related to issues of (a) students who were not prepared, (b) complying with university and department requirements, (c) attending meetings, (d) heavy workload, and (e) understanding process and systems technology (McLean, 2006).

\section{Strategies for Coping with Stress}

Findings from a study conducted in 2011 indicated the following coping strategies for faculty to reduce stress: (a) finding time to exercise even if just a few minutes every hour, (b) being spiritual, (c) managing time effectively, (d) making time to spend with family and friends, and (e) saying no to extra demands on your time when you feel you are or will be overloaded (Iqbal \& Kokash, 2011). The findings also concluded that educational leaders should strive to include faculty in whole-systems decision making on changes in technology, programs, and processes so faculty feel part of the wholesystems thinking with regular communication and faculty support (Iqbal \& Kokash, 2011).

\section{Survey Results}

The results included trends that further identify factors related to stress. Findings were generated from participants who shared their experiences with instructing courses online and their stress level. Our findings are based on an anonymous dataset. 
Smith, Brashen, Minor, \& Anthony, 2015

\section{Key Demographics}

One hundred surveys were returned: $43.4 \%$ of the participants were male, and $54.6 \%$ of the participants were female. Contributing faculty represented $69.7 \%$ of the participants. Contributing faculty was defined as faculty members who teach part-time. Core faculty represented $10.1 \%$. Core faculty was defined as full-time faculty members who are employed on a yearly salary, teach a fulltime load of 18 instructional units per year, and perform related administrative tasks. Eight percent of participants had 0-8 years of experience, while $41.4 \%$ had $6-10$ years of experience teaching in the online environment. Other participants with 11-15 years of experience represented $27.2 \%$ of the sample, and $11.1 \%$ had 16 or more years of experience. The majority (56.6\%) of the respondents included individuals born between 1946 and 1964, while the minority of 1\% included individuals born after 1981. Individuals born between 1925 and 1945 represented $12.1 \%$, and $10.1 \%$ of respondents were born between 1965 and 1981.

\section{Overall Stress Level}

The overall stress level for online faculty included $49.5 \%$ of respondents stating that they experience a high level of stress. Of the other participants, $18.1 \%$ stated that they experience a very high level of stress, while $17.1 \%$ shared that they experience a moderate level of stress. A low level of stress included $10.1 \%$ of respondents. Zero percent of respondents stated that they experience a very low level of stress.

\section{Biggest Work Stressors}

The top biggest work stressors noted by respondents included the following: time constraints, technological issues, and large class sizes. Forty-two participants noted that time constraints had the largest impact on stress. Time constraints included returning multiple papers within a 1-week time span (due to feedback policies), posting final grades within 1 week, unrealistic and/or unexpected deadlines, and rigorous timelines related to participating in discussions actively and substantively. Eleven of the respondents noted technological issues including issues in the Blackboard system as stress inducers. Nine of the participants noted that large class sizes were stress inducers with not enough time to connect with students.

Other issues noted by participants included stress induced by student behaviors, which encompass (a) students not submitting work on time, (b) students not applying feedback instructors offer, (c) students who think they know more than the instructor, (d) students who are going through a stressful situation themselves and need support, (e) students who are unprofessional to the instructor and/or classmates, (f) students who do not adhere to course rubrics but still expect a passing grade, and (g) student complaints.

\section{The Impact of Stress on Work Performance}

Respondents noted that stress does affect their work performance: $55 \%$ of participants noted that stress impacts their work performance very much so, while $34.3 \%$ of respondents stated that stress impacts their work performance somewhat. Zero respondents noted that stress does not impact their work performance. 
Smith, Brashen, Minor, \& Anthony, 2015

\section{Stress Management}

Two percent of respondents stated that they managed their stress somewhat. Other participants $(32.3 \%)$ noted that they managed their stress well. The majority of respondents stated that they managed their stress very well.

\section{Impacts of Online Teaching and Stress Level}

Because the respondents were all online instructors, a question was asked to explore how much their stress level impacted their online teaching. Over 60\% (60.5\%) of participants stated that their online instruction was affected by their stress level. Only $18.3 \%$ stated that their instruction was somewhat affected. Zero percent of respondents noted that their performance was affected hardly at all by stress.

\section{Biggest Stress Symptoms}

The next question involved selecting the types of symptoms that appeared to be a pattern because of stress. An overwhelming number of participants said sleep disturbances occurred because of their stress level: $45 \%$ noted trouble with sleep patterns. Additionally, 40\% felt extremely impatient; $35 \%$ noted tight, tense muscles; $34 \%$ said their level of irritability was higher than normal; $32 \%$ had feelings of being overwhelmed throughout the day; $31 \%$ felt they overate due to a higher stress level; $20 \%-30 \%$ of the participants noted their work quality suffered, had feelings of resentfulness, anger, anxiousness, and engaging in wasted activities. Between $10 \%$ and $20 \%$ of respondents noted eye problems, being fearful, feelings of helplessness, higher than normal sugar use, and an upset stomach. Other symptoms noted by participants included difficulty making decisions, using alcohol, trouble breathing, sweating, dizziness, heart palpitations, confusion, and loneliness.

\section{Specific Ways Instructors Manage Stress}

The majority of the respondents stated that they manage stress through exercise, with over 20 participants noting that exercise helped relieve stress. In addition, all respondents noted that they participate in some type of stress management. The second highest form of stress management included nine participants stating that meditation, quiet time, and reflection are effective. Other forms of stress management included having breaks and down time (noted by six participants), time management (as stated by five respondents), and leisurely walking, with four respondents, came in next in popularity. Results showed that most participants had one stress-management approach.

\section{Biggest Impact of Stress: Online or Face-to-Face?}

Participants noted that the biggest impact of stress was felt in the online sector. Over $67 \%$ (67.7\%) stated that the online environment had the biggest effect on stress. A smaller number of respondents $(32.2 \%)$ stated that face-to-face environments had an impact on their stress level.

\section{Resources}

The majority of respondents (77.8\%) did not know if the university provided stress-management services for virtual faculty. Seven percent of participants stated that the university does provide services. Other respondents (15.1\%) stated that the institution does not provide services for online faculty. 
Smith, Brashen, Minor, \& Anthony, 2015

\section{Analysis of Data}

\section{Themes}

After a thorough analysis, three major themes emerged. All participants experienced stress of some level, with $50 \%$ experiencing a high level of stress. Some of the major factors causing stress to the majority of online faculty were lack of time, high volume of work, and unrealistic timeline expectations from the school. With increasing class sizes, most felt the time expectations caused them increased stress.

All respondents noted that they felt their work performance suffered from their increased stress level. They saw a direct correlation between quality of work and amount of stress. Participants noted that the quality of their work was lower when their stress level was higher. They also strongly felt and noted that it was the online work that caused their stress levels to increase. One may be lead to the conclusion that stress in the online environment is affecting faculty's work in a negative manner. Stress affects instructor performance and could potentially impact the student.

Finally, the effects of stress caused the majority of respondents sleep issues and high levels of anxiety. This included restless sleep and insomnia. All participants stated that they engaged in some personal stress-management activity to relieve the devastating effects. Ways of coping with stress included exercise, meditation, walking, and listening to music. Unhealthy methods, such as overeating and drinking alcohol, were also noted.

The majority of respondents, $78 \%$, were not aware of any stress-management program available to online faculty by the university. Some respondents noted that, if services were available, part-time faculty members do not have access due to lack of benefits. One respondent noted services were available through health insurance.

\section{Recommendations}

The results of this study have demonstrated that stress of online instructors occurs in higher education. One hundred surveys were returned, with $18.1 \%$ of respondents identifying a very high level of stress and $49.5 \%$ of respondents identifying a high level of stress. Stress can negatively impact instructors' attitude and performance. Fifty-five percent of respondents identified stress as very much affecting attitude and performance. Though a certain amount of stress (eustress) is good, too much stress (distress) can affect attitude, performance, and sustainability of performance over time. Stress is easy to ignore for the short term. The danger is that the symptoms may creep up, and soon, the recipient is not aware that he or she is experiencing them. It is similar to catching a cold. Many people might feel miserable at the onset of a cold, but over time, they get used to it and just go about their daily routine. What happens is that feeling sick becomes the norm, and individuals do not realize that they are feeling poorly. Though many in this study felt like they were managing stress well, they may not be managing it as well as they could be. As evidenced in the results, most respondents had mainly one stress-management approach. It would be prudent to have multiple choices for managing stress. One technique may not always work, or the opportunity to use that technique might not always be present. The comprehensive stress-management plan outlined here is designed to enable participants to manage stress more effectively. This plan includes the following steps:

1. Identify symptoms of stress 
Smith, Brashen, Minor, \& Anthony, 2015

2. Analyze own stress level

3. Assess causes of stress

4. Identify and implement stress-management techniques

5. Attack causes of stress

6. Assess progress

\section{Symptoms of Stress}

Not everyone experiences physical manifestations of stress. There are individuals who are under high stress but don't recognize any symptoms while literally stewing in their own juices (Eliot \& Breo, 1989). If one doesn't recognize stress symptoms, the temptation may be to conclude that stress is not a problem for them. However, if it is a problem and it is not addressed, the results could be devastating. Those who can identify symptoms of stress when they occur are in a better position to deal with it. Those who are not able to identify symptoms would be well served to develop a stressmanagement program to prevent the ultimate effects of untreated stress.

The survey used in this study provided an assessment of stress symptoms. This assessment could serve as a guide for identifying stress symptoms. One may argue, for example, that a headache may not be caused by stress and may just be a headache. That may be true. A good test for someone who identifies stress symptoms is to see if those symptoms sustain themselves when the underlying cause of the stress is removed. Unfortunately, one cannot remove all causes of stress, but there are opportunities to mitigate stress inducers. The stress-management programs introduced in this article provide the reader with tools and techniques to lessen stressors that the reader may not be in a position to control. For example, one might have to deal with a coworker or boss who is challenging; however, this individual, for various reasons, may not be willing, or able, to change jobs. For this reason, the most viable option is to apply tools to manage the stress.

\section{Analyze Own Stress Level}

Once symptoms are identified, and if these symptoms tend to be a pattern, one can begin to analyze their impact. Do the symptoms coincide with something going on in one's life? For example, one may get an upset stomach and anxiety when having to interact with a mean coworker or a troublesome relative. For example, one may get an upset stomach and feel anxiety less when the person removes him- or herself from the presence of a toxic person? If so, it is likely that the relationship with that person is causing the stress. Once we can recognize how stress affects us, we are in a better position to address it (Sood, 2013). We can either treat the symptom by using stress-management techniques, treat the cause by resolving the conflict, or both. The person assessing their stress level needs to focus on how he or she is thinking and feeling. Is the individual willing to put up with the stress and how is it impacting them mentally, emotionally, and physically?

\section{Access Causes of Stress}

There are many underlying causes of stress that exist in our lives. These many causes can be broken down into three major buckets: (a) self-esteem issues, (b) people problems, and (c) time-management challenges. Self-esteem can be defined as the sum of all of one's feelings about self. The better a person feels about themselves, the higher the self-esteem. If a person doesn't feel good about themselves, he or she is more likely to experience stress because of the concern of feeling insignificant. When one has a conflict or is unable to get along with certain people, it is symptomatic of people problems. When people feel overwhelmed, overworked, or that there are just not enough 
hours in the day, they typically are experiencing time-management problems. The results of this study suggest that lack of time, increased class size, and volume of work are major stressors for many of the respondents.

The techniques introduced here might be enough to manage everyday stress without addressing the causes. If that is not the case, and one has to do more stress management with diminishing returns, then it is important to look at addressing the causes. For example, a client of one of the authors of this article had a coworker who was extremely difficult. Therefore, the client ran every day at lunch or meditated to maintain a more effective balance. Some individuals may be able to sustain themselves with this approach without undue stress. However, in this case, the stress-management techniques no longer worked, so it was advisable for this client to address the cause, which, in this case, was the relationship with the coworker.

It is beyond the scope of this article to provide solutions to causes of stress. Instead, the focus here is to identify tools and techniques that will make people stronger and better able to cope with stress while the cause may still remain.

\section{Identify and Implement Stress-Management Techniques}

\section{Physical Activity}

Physical activity does not necessarily need to be aerobic for it to be beneficial. Playing golf, bowling, shooting hoops, hiking, and sailing are all examples of physical activity that may bring pleasure and relieve stress. Aerobic exercise might include running, power walking, power hiking with a heavy pack, swimming, using cardio machines, cross-country, skate skiing, and rowing. Skate skiing is a highly aerobic form of cross-country skiing in which faster and longer skis are used and participants use an ice-skating motion.

These exercises all can result in endorphins that the body releases during exercise. The endorphins interact with the receptors in a person's brain that reduce their perception of pain. When endorphins kick in, one may experience euphoria (Health Harvard, 2011). Whether one is doing aerobic exercise or not, it is important to see a doctor first to assess overall health. People who do not seek medical advice may either have hidden health issues or may not be in shape for vigorous exercise and run the risk of injury or burnout. The keys to a successful exercise are selecting an activity that is enjoyable, getting the appropriate equipment to lessen the possibility of injury, and taking lessons or using a coach. It is a good idea to set up a regular exercise schedule that works for each individual attempting this and then follow up on the identified plans. Making exercise a habit is key. Regularly exercising can not only positively impact the body, but can also contribute to heightened morale. Exercising on a regular basis promotes stress reduction. Thirty to 40 min of moderate activity on most days, such as walking, or 15-20 min of vigorous exercise will bring about this benefit (Health Harvard, 2011).

\section{Constructive Self-Talk}

Constructive self-talk uses our positive self-talk to allow us to choose how we feel. The premise behind constructive self-talk is that the user focuses on thinking positively rather than negatively. The idea is that we become like the pictures we create in our minds. If we see something as negative, we are more likely to experience it that way. By focusing on the positive, negative thinking is 
minimized, and we set ourselves up for a positive outcome. Examples include positive denial, systematic desensitization, reprogramming negativity and creative visualization.

\section{Positive Denial}

This technique can be used when there is a situation that may bring about stress. One temporarily disregards situations that have not occurred and may not ever occur. For example, one of our colleagues was giving a big presentation in Minnesota in the dead of winter and was scheduled to fly in January from Atlanta, Georgia, to Minnesota. She was stressed from worrying that her plane could be delayed or cancelled. One could stew about this for weeks. The positive denial technique allows people to schedule their worrying. For example, our colleague postponed her worrying until the day of the flight because there was nothing she could do to influence the situation. Just as one schedules a task in Microsoft Outlook, one can schedule when to start worrying. It also helps to have a game plan in the event that the worrying turns out to be merited (Lazarus, 1997).

\section{Systematic Desensitization}

Wolpe (1958) introduced a behavioral therapy technique developed in the 1950s, which was designed to overcome a phobia. For example, if one abhorred conflict and had to do a performance review with an unpleasant individual, the subject would be trained to imagine the situation and then, as stress set in, do a relaxation exercise. Then, one would pick it up again thinking of an even worse scenario. Alternately relaxing and visioning the situation could lead to overcoming the phobia. We are using this technique a little differently here. What we recommend is to think about a situation that causes stress and then imagine the worst-case scenario. Then come up with a game plan. Let's take the previous example of worrying about the plane being late or cancelled. What is the worst thing that could happen? Would you die? Would you go to jail? Well, you could be late for your presentation, miss your flight altogether, and lose the contract. If this happened, what would be your game plan? What may relieve the stress is having an actual plan in place if the worst-case scenario occurs.

\section{Reprogramming Negativity}

Stress is often exacerbated by negative thinking. For example, one may be teaching a class and find that the operating system's platform is running very slow, the class is too large to manage, grading must be done over the holidays, and pay does not meet living costs. We can turn this around by focusing on the positive instead. For example, in the situation here, the positive cognitions might include the ability to work when and where we choose, to not have a commute, to not have to dress up for work, to have interesting and eager students. We all have the power to choose what we think and feel (Gawain, 2002; Sood, 2013).

\section{Creative Visualization}

Creative visualization is accomplished by picturing a situation yet to happen in the most positive way possible. For example, a well-known keynote speaker often got very nervous before a training session. He would then visualize the room, the set-up, and the participants in the most positive way. He would visualize that the participants could not wait to get to the training and were very excited about it. Upon his visualization it did not matter how the audience felt because he would come in with a positive attitude and would have a much better impact than if he came in with a negative demeanor. When he saw the energetic and smiling audience, his stress level was mitigated. Creative visualization has been shown to promote positive changes in one's life (Gawain, 2002). 


\section{Relaxation Exercises}

Relaxation exercises are designed to have a calming effect and relieve stress (Sood, 2013). Most can be applied almost anywhere. Here is an example of a simple relaxation exercise: Close your eyes, relax, and take a few deep breaths. Then, beginning with your toes, tense and relax each muscle group all the way to your head. This should include toes, feet, ankles, calves, thighs, hips, stomach, buttocks, arms, hands, fingers, shoulders, neck, throat, and head. By the time one gets to the head, the relaxation kicks in (Sood, 2013).

Another option is a meditative exercise. Sit quietly in a chair with your feet comfortably on the floor and your hands on your knees, palms down. Close your eyes (though some prefer doing this with eyes open). Take a few deep breaths and concentrate on your breathing. Think of a sound or a picture (perhaps waves in the ocean) in your mind. Focusing on this will enable you to keep the endless thoughts at a minimum so you can focus on the here and now. These types of exercises can reduce one's stress level and can be done individually (Sood, 2013).

\section{Networking}

Oprah Winfrey (n.d.) has said that to enhance self-esteem, we simply need to surround ourselves with people who lift us higher. The key to networking is to have more than one person to spend time with who will be supportive. For this exercise, one needs to think about his or her support system. Then he or she should make a list of each supporting person, how often contact is made, who initiates, how the person is helpful, and the overall feeling after the interaction. One colleague did this exercise and realized her network had diminished because she stopped contacting people in her network. She rationalized that she was too busy. For networks to be effective, there has to be a mutual initiation. People often get different things from those in their network. For example, one might have someone with whom he or she only plays golf, and someone else with whom to go to the opera, and perhaps someone to just talk with over a meal. The key is to utilize the network to relieve stress (Health Harvard, 2011).

\section{Quick and Effective Coping Skills}

Here is a list of approaches that can be done quickly and individually.

- Plan a little idleness in each day. This gives one the opportunity to reenergize. Stillness can promote stress relief (Iyer, 2014).

- Laugh. Studies have shown that laughter can stimulate the immune system and help to alleviate stress (Cousins, 2005).

- Practice deep breathing. Breathing exercises can be quickly learned in minutes. One can experience stress relief by doing these simple exercises regularly (M. Davis, Robbins Eshelman, \& McKay (2008).

- Do something nice for yourself each day. This might be listening to music, calling a friend, engaging in an enjoyable activity, taking a hot bath, or anything else that brings pleasure.

- Make sure your body is nourished (M. Davis et al., 2008) and you get enough sleep (K. Davis, 2015).

- Do not structure your leisure time. Simply enjoy leisure time without a set schedule always in place. Schedules can often be tight and stressful.

- Keep a journal. Getting one's thoughts down in writing can relieve stress (Akula, 2015). 


\section{Saying No}

One way to address being overcommitted is to be able to say no. It may not be easy to say no, but it can alleviate stress Saying no works best when you do not do it all the time. Say yes whenever you can. The following are some tips in how to say no:

- Listen to the request all the way through.

- Make a self-disclosing statement demonstrating empathy (e.g., "It's too bad that happened," "It does sound like you are in a bind").

- Say "NO" (e.g., "No, I am not going to be able to do that for you now"; other options might include, "Let me think about whether I can do it and I'll get back to you by 3 p.m.," "Yes, I can do that if you'll provide ...").

- If appropriate, explain why you are saying no (e.g., lack of time, other priorities).

- End with an alternative or some suggestion, which gives the other person a course of action (e.g., "Have you thought about ...?" "Try me later." Tip: You don't have to solve the problem for the other person).

- Be prepared to assertively repeat the no.

\section{Causes of Stress and Relationship to Online Instructors}

Again, it is beyond the scope of this article to diagnose causes, but if the stress-management programs are not enough to manage the stress, then causes should be addressed. The data revealed a need for the school to examine current workload, timeline expectations, and overall factors surrounding the online environment. Because all respondents experience stress and feel it impacts job performance, attention needs to be given to a plan to help reduce these levels.

\section{Assess Progress}

Once a stress-management program is in place, it is important to check in with yourself and assess your stress level. The stress-management programs can be adjusted to meet the needs of the individual. If one feels less stress overall when applying stress-management techniques, then the individual is moving in the right direction. Stress is fluid and changes so constant, assessment of progress is important. It is useful while assessing progress to check in with those that know you and incorporate their feedback into your analysis.

One size does not fit all when it comes to managing stress. Because the results of this study include data that substantiate the point that online instructors experience stress, and because there appears to be no stress-management program or wellness program available to online instructors, it is recommended that individuals experiment with the techniques suggested in the recommendations until finding one or more that promotes positive results. A certain amount of stress is desirable, but when stress is not addressed, it can lead to burnout, poor performance, and low morale. 


\section{References}

Akula, S. (2015). Epic journaling: The ultimate guide to achievement (2nd ed.). Seattle, WA: Plaid Enterprises.

American Institute of Stress. (n.d.) Workplace stress. Retrieved from http://www.stress.org/workplace-stress/

American Psychological Association. (2011). APA survey finds many U.S. workers feel stressed out and undervalued. Retrieved from http://www.apa.org/news/press/releases/2011/03/workersstressed.aspx

American Psychological Association. (2012). Stress in the workplace. Retrieved from http://www.apa.org/helpcenter/workplace-stress.aspx

Betonio, J. (2015). Stress factors and the teaching performance of college faculty. International Journal of Social Sciences and Humanity, 5, 651-655.

Center for the Promotion of Health in the New England Workplace. (2015, January 1). How costly is job stress? Retrieved from http://www.uml.edu/Research/Centers/CPH-NEW/stress-atwork/financial-costs.aspx

Cousins, N. (2005). Anatomy of an illness as perceived by the patient. New York, NY: W. W. Norton \& Company.

Davis, K. (2015). Sleep: Proven tips to increased energy, feeling better, and defeating insomnia. Seattle, WA: Amazon Digital Services, Inc.

Davis, M., Robbins Eshelman, E., \& McKay, M. (2008). The relaxation and stress reduction workbook (6th ed.). Oakland, CA: New Harbinger Publications.

Eliot, S., \& Breo, D. (1989). Is it worth dying for? New York, NY: Random House.

Friedman, M. \& Rosenman, R. (1974). Type A behavior and your heart. San Francisco, CA: Alfred A. Knopf Publications.

Gawain, S. (2002). Creative visualization. Novato, CA: Nataraj Publishing.

Health Harvard. (2011, February 1). Staying healthy: Exercising to relax. Retrieved from http://www.health.harvard.edu/staying-healthy/exercising-to-relax

Iqbal, A. \& Kokash, H. (2011). Faculty perception of stress and coping strategies in a Saudi private university: An exploratory study. International Education Studies, 4, 137-149.

Iyer, P. (2014). The art of stillness: Adventures in going nowhere. New York, NY: Simon \& Schuster.

Lazarus, R. S. (1997). Fifty years of the research and theory of R. S. Lazarus: An analysis of historical and perennial issues. Mahwah, NJ: Lawrence Erlbaum Associates Inc.

Maslach, C., Jackson, S., \& Leiter, M. (1996). Maslach burnout inventory manual (3rd ed.). Palo Alto, CA: Consulting Psychologists Press.

Mazzetti, G., Schaufeli, W. B., \& Guglielmi, D. (2014, February 3). Are workaholics born or made? Relations of workaholism with person characteristics and overwork climate. International Journal of Stress Management, 1, 1-28. doi:10.1037/a0035700

McLean, J. (2006). Forgotten faculty: Stress and job satisfaction among distance educators. Online Journal of Distance Learning Administration, IX, 1-3. 
Miller, W. (1994). Teacher stress in variable calendar schools compared to teacher stress in traditional calendar schools. Dissertation Abstracts International Section A, 1-101. Retrieved from http://psychology.wikia.com/wiki/Junior_high_school_teachers___Dissertations

Ross, D., \& Vasantha, S. (2014). A conceptual study on impact of stress on work-life balance. Sai Om Journal of Commerce \& Management, 1, 61-65.

Singh, A., Tripathi, V., \& Yadav, P. (2010). Workplace stress among technical and management faculty: An investigative study. A Management Journal, 2, 181-216.

Sood, A. (2013). The Mayo Clinic guide to stress-free living. Philadelphia, PA: Decape Press.

Stress. (2011, May 9). In Symptomfind. Retrieved on June 1, 2015 from http://www.symptomfind.com/diseases-conditions/stress/

Winfrey, O. (n.d.). BrainyQuote.com. Retrieved June 6, 2015, from http://www.brainyquote.com/citation/quotes/quotes/o/oprahwinfr383697.html\#RoK35aUgO1v ozi2x.99

Wolpe, J. (1958). Psychotherapy by reciprocal inhibition. Stanford, CA: Stanford University Press.

UCLA Faculty Diversity \& Development. (2013). Balancing work and life as an assistant professor. Retrieved from https://faculty.diversity.ucla.edu/resources-for/work-life/family-friendlyacademy/balancing-work-and-life-as-an-assistant-professor

The Journal of Social Change, sponsored by Walden University, welcomes manuscripts focusing on interdisciplinary research in social change that improves the human condition and moves people, groups, organizations, cultures, and society toward a more positive future.

Walden University Publishing: http://www.publishing.waldenu.edu 